\title{
The partial reinforcement effect after minimal acquisition: Single pellet reward, spaced trials'
}

GARVIN McCAIN, University of Texas at Arlington, Arlington, Tex. 76010

Achievement of a PREE following a small number of trials has posed a problem for several explanations of the PREE. The use of single or multiple pellets is also important to some of the explanations. In the present study the usual PREE was achieved using a single pellet and spaced trials.

The achievement of a PREE following a small number of triais finally seems to be an accepted phenomenon (McCain, 1966; Spence et al, 1965; Capaldi \& Deutsch, 1967; Amsel et al, 1968). There remain questions of interpretation as well as questions about some empirical aspects of these studies. One problem which involves both empirical and theoretical consideration is whether and under what conditions the PREE can be achieved using a single pellet as reward. Amsel et al (1968) and McCain (1968) have considered this problem in some detail. Amsel achieved a PREE using a 24h ITI with multiple pellets, but not with single pellets. The object of the present study was to determine whether the PREE could be achieved with a small number of spaced trials and a single-pellet reward.

SUBJECTS AND APPARATUS

The Ss were 31 naive Long Evans rats from the University of Texas at Arlington colony. All Ss were approximately 90 days old at the beginning of the study. The test apparatus was a straight alley. Photoelectric cells were arranged so that four measures were taken, Run 1 (R1), Run 2 (R2), Goal (G), and Full-alley. The first two measures were taken close to the middle of the alley, while the goal measure began 18 in. from the goal cup. The alley is more fully described in McCain (1968).

\section{PROCEDURE}

Subjects were maintained on a 23-h deprivation schedule for 12 days. During this period, and on the test day, the usual handling, exploration, randomization, balancing, and running procedures were used (see McCain, 1968). The only change in pretraining was that $S s$ were given access to one 500-mg Noyes pellet in their home cages on Days 9-12. On Day 13, Ss in Group P received five acquisition trials with a RNRNR reinforcement pattern. Group C was reinforced on each acquisition trial. A

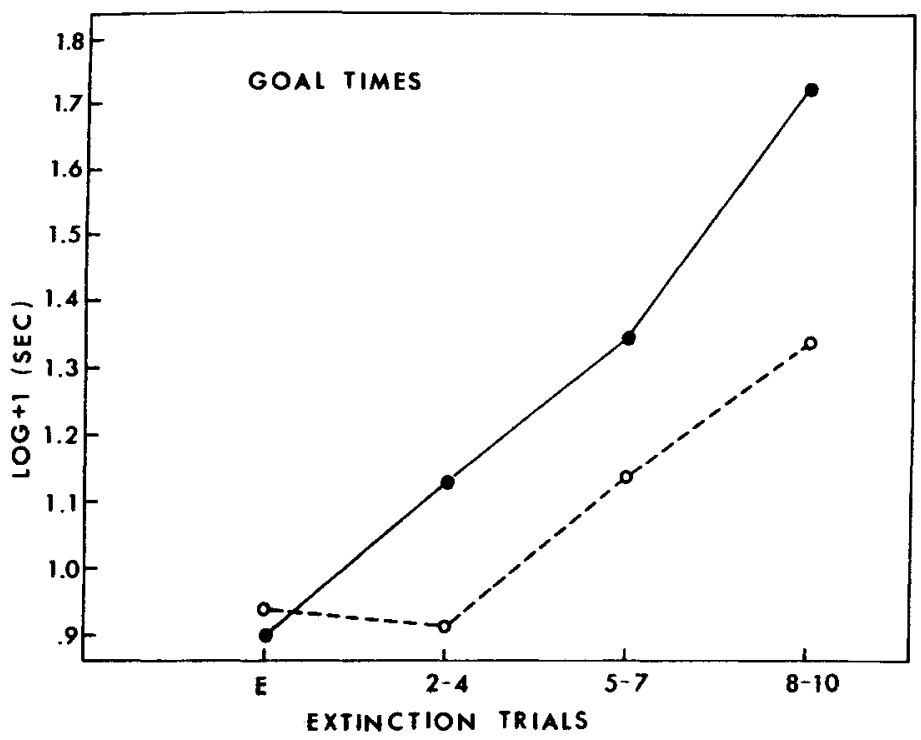

Fig. 1. Mean median extinction times for goal section of nunway. single $500-\mathrm{mg}$ Noyes pellet was used as a reinforcer. Ss remained in the goal box (GB) until the pellet was consumed or were confined for $30 \mathrm{sec}$ on nonreinforced trials. All Ss were given 10 extinction trials, being confined to the GB for $20 \mathrm{sec}$ on each trial. In both acquisition and extinction $S s$ were run in squads of six with each $S$ in the squad given a single trial in rotation. This procedure gave an approximate 15 -min ITI in acquisition and extinction.

\section{RESULTS AND DISCUSSION}

As may be seen from Fig. 1,Ss in Group $P$ ran faster in extinction than Group C. Due to space limitations only goal data are shown; other data are available from the author. The differences were significant in each section of the runway. With $\mathrm{df}=1 / 29$ in each case, results were: $R 1, F=4.98$, $\mathrm{p}<.05 ; \mathrm{R} 2, \mathrm{~F}=4.88, \mathrm{p}<.05 ; \mathrm{G}, \mathrm{F}=7.25$, $\mathrm{p}<.015$; Full-alley, $\mathrm{F}=4.66, \mathrm{p}<.05$. As has been found often in the past, the largest differences were present in the goal area. In addition to the results reported above, the centered $60 \%$ of the scores were analyzed as described in McCain (1968). With df $=1 / 17$ in each case, the results were: $R 1, F=5.39$, $\mathrm{p}<.05 ; \quad \mathrm{R} 2, \quad \mathrm{~F}=7.38, \quad \mathrm{p}<.025 ; \quad \mathrm{G}$, $F=17.26, p<.001 ;$ Full-alley, $F=19.40$, $\mathrm{p}<.001$. In each analysis Group $P$ was more resistant to extinction than Group $C$. Again, the use of the centered scores seems to be useful where a small number of acquisition trials are used.

The present study together with McCain (1968) and Howlett \& Sheldon (1968) indicates it is quite possible to achieve a PREE using a single-pellet reward and that a 15-min ITI does not create any serious difficulty in achieving such a result.

\section{REFERENCES}

AMSEL, A., HUG, J. J., \& SURRIDGE, C. T Number of food pellets, goal approaches, and the partial reinforcement effect after minimal acquisition. Joumal of Experimental Psychology, 1968, 77, 530-534.

CAPALDI, E. J., \& DEUTSCH, E. A. Effects of severely limiting acquisition training and pretraining on the partial reinforcement effect. Psychonomic Science, 1967, 9, 171-172.

HOWLETT, J. C., \& SHELDON, M. H. Effects of partial delay of reinforcement following a smal number of acquisition trials. Psychonomic Science, 1968, 11, 259.

McCAIN, G. Partial reinforcement effects following a small number of acquisition trials. Psychonomic Monograph Supplements, 1966, 1,251-270.

McCAIN, G. The partial reinforcement effect after minimal acquisition: Single pellet reward. Psychonomic Science, 1968, 13, 151-152.

SPENCE, K. W., PLATT, J. R., \& MATSUMOTO, $R$. Intertrial reinforcement and the partial reinforcement effects as a function of number of training trials. Psy chonomic Science, 1965, 3, 205-206.

NOTE

1. This research was supported by NIMH Grant 14686-01. Thanks are due to Ronald T. Constant who ran the Ss. 